\title{
Pesticide Residue Determination in Groundwater using Solid-Phase Extraction and High-Performance Liquid Chromatography with Diode Array Detector and Liquid Chromatography-Tandem Mass Spectrometry
}

\author{
Sergiane S. Caldas, Adriana Demoliner, Fabiane P. Costa, \\ Marcelo G. M. D'Oca and Ednei G. Primel** \\ Post-graduation Program in Technological and Environmental Chemistry, Escola de Química e \\ Alimentos, Universidade Federal do Rio Grande - FURG, Av Itália, $\mathrm{km} 8 \mathrm{~s} / \mathrm{h}$, \\ 96201-900 Rio Grande-RS, Brazil
}

\begin{abstract}
Resíduos de quatro agrotóxicos foram determinados durante um ano em águas de poços de uma área agrícola no Sul do Brasil. Os métodos para a separação, identificação e quantificação dos compostos incluíram cromatografia líquida de alta eficiência com detecção por arranjo de diodos (HPLC-DAD) e cromatografia líquida acoplada à espectrometria de massas (LC-ESI-MS/MS). Uma etapa de pré-concentração baseada na extração em fase sólida com cartuchos de $200 \mathrm{mg}$ de C18 foi realizada. Todos os parâmetros analíticos ficaram de acordo com os limites sugeridos para a validação de métodos cromatográficos. Os limites de quantificação para o método, considerando um fator de pré-concentração de 250 vezes, foram $0,2 \mu \mathrm{g} \mathrm{L}^{-1}$ para todos os analitos por HPLCDAD, 4,0 $\mathrm{ng} \mathrm{L}^{-1}$ para o clomazona, carbofurano e tebuconazol e 40,0 $\mathrm{ng} \mathrm{L}^{-1}$ para o 2,4-D por LC-ESI-MS/MS. Nas amostras de águas subterrâneas, o 2,4-D não foi detectado e o carbofurano, clomazona e tebuconazol apresentaram concentrações que variaram entre 0,25 e $10,40 \mu \mathrm{g} \mathrm{L}^{-1}, 0,20$ e $0,82 \mu \mathrm{g} \mathrm{L} \mathrm{L}^{-1}$, e 0,20 e $4,16 \mu \mathrm{g} \mathrm{L}^{-1}$, respectivamente. Os métodos mostraram-se adequados para a determinação de agrotóxicos em águas subterrâneas.
\end{abstract}

Residues of four pesticides in groundwaters were surveyed during one year in an agricultural area in southern Brazil. The methods for separation, identification and quantification of the compounds included high-performance liquid chromatography with diode array detection (HPLCDAD) and liquid chromatography with electrospray interface tandem mass spectrometry (LC-ESIMS/MS). A pre-concentration step based on solid-phase extraction with $200 \mathrm{mg} \mathrm{C} 18$ cartridges was applied. All the analytical parameters were within the limits suggested for the validation of chromatographic methods. The LOQs for the methods, considering the 250 -fold pre-concentration step, were $0.2 \mu \mathrm{g} \mathrm{L}^{-1}$ for all pesticides by HPLC-DAD, $4.0 \mathrm{ng} \mathrm{L}^{-1}$ for clomazone, carbofuran and tebuconazole and $40.0 \mathrm{ng} \mathrm{L}^{-1}$ for 2,4-D by LC-ESI-MS/MS. In groundwater samples, 2,4-D was not detected, and carbofuran, clomazone and tebuconazole were detected in concentrations ranging from 0.25 to $10.40 \mu \mathrm{g} \mathrm{L}^{-1}$, from 0.20 to $0.82 \mu \mathrm{g} \mathrm{L} \mathrm{L}^{-1}$ and from 0.20 to $4.16 \mu \mathrm{g} \mathrm{L}^{-1}$, respectively. The methods proved to be adequate for the analysis of pesticides in groundwaters.

Keywords: groundwaters, pesticides, HPLC-DAD, SPE, LC-MS/MS

\section{Introduction}

Water contamination by pesticides has been an important topic of study over the last few years. In Brazil, there are some studies that report the presence of pesticides in surface water. ${ }^{1,2}$ However, these compounds, in particular the most polar ones, through processes of run-off, spray drift and leaching, can easily reach surface waters and

*e-mail: eprimelfurg@gmail.com possibly contaminate groundwater. ${ }^{3}$ In some areas in Brazil, where pesticides are widely used, mainly due to agricultural activities, some pesticides have been found in groundwater. ${ }^{4,5}$

The use of pesticides worldwide includes numerous compounds with different functionalities over a wide range of polarity and solubility. The target analytes selected for this work belong to different classes, carbamates (carbofuran), acidic herbicides (2,4-D), isoxazolidinones (clomazone) and triazoles (tebuconazole). Carbamates form 
one of the major classes of synthetic organic pesticides and are used annually on a large scale worldwide. They are usually distributed in aqueous environments because of their high solubility in water. ${ }^{6}$ The acidic herbicide 2,4-D has poor biodegradability and has frequently been detected in water courses; it is widely used in southern Brazil due to its low cost and good selectivity. ${ }^{7,8}$ The class of triazoles includes many of the most modern agricultural fungicides such as tebuconazole. Most of these triazole fungicides are used against rust, powdery mildews and scabs. ${ }^{9}$ The herbicide clomazone, which belongs to the class isoxazolidinone is particularly used against species of annual broadleaf weeds and grass. It is highly soluble in water and has potential for groundwater contamination. ${ }^{10,11}$

In Brazil, Resolution No. 396 (http://www.mma.gov. br/port/conama/legiabre.cfm?codlegi=562, 2008), issued by the National Council of Environment (CONAMA), establishes the concentration accepted for each individual pesticide in groundwater intended for domestic supply. The Brazilian legislation does not include the pesticides clomazone and tebuconazole; for 2,4-D, the maximum value accepted is $30 \mu \mathrm{g} \mathrm{L}^{-1}$ and for carbofuran, it is $7 \mu \mathrm{g} \mathrm{L}^{-1}$.

Determination of pesticides in environmental waters can only be evaluated by sensitive methods and such work requires methods for detecting and identifying the compounds with the fewest number of steps. ${ }^{12-14}$ The ideal sample preparation methodology should be fast, accurate and precise, besides, it should consume little solvent. Solid-phase extraction (SPE) is a good alternative to prepare samples for chromatographic analysis, owing to its simplicity and economy in terms of time and solvent needs, and it offers the possibility of reducing sample volume without loss of sensitivity and minimizing sample manipulation. ${ }^{13,15}$ In the isolation and pre-concentration of pesticides from aqueous samples, before the liquid chromatography (LC) analysis, the most used sorbents in SPE are C18-bonded silicas and styrene-divinylbenzene co-polymers..$^{14,16-18}$

For the analyses of pesticide residues in water samples, LC combined with diode array detection (DAD), has been used. ${ }^{19-21}$ The last is a complementary method which supplies the spectra of the compound, thus, providing an additional way to confirm the peak identity. ${ }^{12}$ However, other techniques, such as the liquid chromatography coupled to mass spectrometry (MS), combine the advantages of chromatography (high selectivity and separation efficiency) and mass spectrometry (structural information and further increase in selectivity), while being relatively straightforward to accomplish. ${ }^{22,23}$

LC-MS is specially powerful for the direct analyses of polar compounds which are subject to thermal decomposition or do not have adequate vapor pressure for GC separations. ${ }^{24}$ Based on the type of interface, LC-MS is also capable of providing structural information to confirm the identification of analytes in a sample. ${ }^{25}$ The mass spectrometer can isolate a selected ion from the target compound and induce its fragmentation by collision and, for this reason, can eliminate any potential interference from the sample matrix, and also from mobile and stationary phases. ${ }^{13}$ LC-MS is currently used for analysis of polar pesticides, including carbamates, triazines and chlorinated phenoxyacids, providing adequate detection limits for residue analysis. ${ }^{26-29}$

The aim of this study was to develop and validate a fast, sensitive and reliable method combining SPE with C18-bonded silica, followed by HPLC-DAD and LC-MS/MS with eletrospray (ESI) interface and its application for the analysis of carbofuran, 2,4-D, clomazone and tebuconazole residues in groundwater samples. The proposed methodology was applied to the determination of these pesticides in 120 samples collected in ten wells in Quitéria, located in Rio Grande, RS, Brazil. This region was selected because of the special characteristics of its agricultural production. Pesticides of different classes are widely used and some of them, due to their physicalchemical properties, can reach groundwater systems which are used for human consumption. For this reason, there is special interest in developing and evaluating analytical methods for this analysis.

\section{Experimental}

\section{Reagents and chemicals}

Carbofuran, clomazone, tebuconazole and 2,4-D analytical standards (purity > 99\%) were supplied by Sigma Aldrich (São Paulo, Brazil). HPLC grade methanol and acetonitrile were supplied by Mallinckrodt (Phillisburg, NJ, USA). Formic (98-100\%) and phosphoric acid (85\%) analytical grade were purchased from Merck (Darmstadt, Germany). Water was purified with a Direct-Q UV3 ${ }^{\circledR}$ (resistivity $18.2 \mathrm{M} \Omega \mathrm{cm}$ ) water purification system (Millipore, Bedford, MA, USA). The SPE extraction cartridges were octadecylsilane (Strata C18-E) with $200 \mathrm{mg}$ of phase, manufactured by Phenomenex (Torrance, CA, USA).

Individual pesticide stock solutions containing $1000 \mu \mathrm{g} \mathrm{mL}{ }^{-1}$ of the target compounds were prepared in methanol and stored at $-18{ }^{\circ} \mathrm{C}$. Intermediate working standard mixtures in methanol, containing $100 \mu \mathrm{g} \mathrm{mL}^{-1}$ for each pesticide, were prepared and used for spiking samples and for preparing the calibration curve. Working standard solutions were prepared monthly while the dilutions used for the calibration curves were prepared daily. 


\section{SPE procedure}

The isolation of the target organic compounds from water samples was performed using a SPE procedure. Water samples, without any filtration, were extracted by solid-phase extraction using cartridges with $200 \mathrm{mg}$ of C18-E whose average particle size is $55 \mu \mathrm{m}$. Cartridges were conditioned with $3 \mathrm{~mL}$ of methanol, $3 \mathrm{~mL}$ of ultrapure water and $3 \mathrm{~mL}$ of ultrapure water $\mathrm{pH} 3.0$, acidified with phosphoric acid 1:1 $(\mathrm{v} / \mathrm{v})$. After the conditioning step, aliquots of $250 \mathrm{~mL}$ of water samples, acidified at $\mathrm{pH} 3.0$ with phosphoric acid (to increase the pesticide retention) were loaded through the cartridges with a flow rate of $6 \mathrm{~mL} \mathrm{~min}^{-1}$. After that, the analytes were eluted with $1 \mathrm{~mL}(2 \times 500 \mu \mathrm{L})$ methanol, volume adjusted in $1 \mathrm{~mL}$ and injected into the chromatographic system. This extraction procedure had been previously developed and optimized in our laboratory. ${ }^{30}$ Phosphoric acid was used because of its low absorption at wavelengths below $220 \mathrm{~nm}$; these were used in HPLC-DAD to determine the compounds in the well samples.

\section{Sampling}

The studies of groundwater contamination with pesticides were carried out in Quitéria, a rural area located near Rio Grande, a city in the southeast of Brazil that has about 185,000 inhabitants. The region of Quitéria is an agricultural area where there are different kinds of production, mainly onion, fruits and vegetables in general. The intense agricultural production, and consequently the use of pesticides, can cause the contamination of groundwaters.

Samples from drinking water wells with depths ranging from 2.5 up to $37 \mathrm{~m}$ were collected in ten sampling points from September 2007 to August 2008, and analyzed to determine the concentration of carbofuran, 2,4-D, clomazone and tebuconazole. Sampling was carried out once per month in each well.

Samples were collected directly in $1 \mathrm{~L}$ amber glass bottles in each sampling site. These bottles had been cleaned prior to sampling by rinsing them three times in the water to be sampled. The bottle was filled to the top with as little remaining air as possible, and sealed tightly. All samples were properly labeled with details of the source and sampling date, and stored at $4{ }^{\circ} \mathrm{C}$ until solid-phase extraction, which was carried out on the same day of sampling.

The samples were acidified to $\mathrm{pH} 3.0$ with phosphoric acid. After extraction of pesticide residues from water, solid-phase extraction, pesticides were determined by LC-ESI-MS/MS.

The selection of the analytes included in this study was based on their extensive use as pesticides in agricultural areas. Moreover, these pesticides are some of the mostly used pesticides in the study area; according to the US Environmental Protection Agency (US EPA) they have potential to reach the groundwater systems (Table 1).

\section{Chromatographic methods}

\section{$H P L C-D A D$}

HPLC-DAD separation was performed using an HPLC apparatus consisting of a column Hyperclone BDS C18 $5 \mu \mathrm{m} 130 \AA$ ( $(250 \times 4.6 \mathrm{~mm}$ i.d. $)$, from Phenomenex, a Waters 600 pump model, associated with a Waters 2996 Photodiode Array Detector, Rheodyne $20 \mu \mathrm{L}$ loop injector, connected to an Empower PDA software for data acquisition. The UV spectra were recorded in the 210-400 $\mathrm{nm}$ range.

For HPLC-DAD analysis, the mobile phase composition was acetonitrile:water $(52: 48, \mathrm{v} / \mathrm{v}), \mathrm{pH} 3.0$ acidified with $\mathrm{H}_{3} \mathrm{PO}_{4} 1: 1(\mathrm{v} / \mathrm{v})$, using a flow rate program of $0.8 \mathrm{~mL} \mathrm{~min}^{-1}$ for $8 \mathrm{~min}$, increasing to $1.2 \mathrm{~mL} \mathrm{~min}^{-1}$ until the $14^{\text {th }}$ min and then $0.8 \mathrm{~mL} \mathrm{~min}^{-1}$ until the $15^{\text {th }} \mathrm{min}$. The mobile phases were degassed for $30 \mathrm{~min}$ in an ultrasonic bath before use. The analyses by HPLC-DAD were based on the method described in Caldas et al..$^{30}$

\section{$L C-E S I-M S / M S$}

Liquid chromatography with mass spectrometric detection was performed in a Waters Alliance 2695

Table 1. Risk assessment of groundwater pollution, based on criteria established by the U.S. EPA

\begin{tabular}{|c|c|c|c|c|c|c|}
\hline \multirow[b]{2}{*}{ Pesticide } & \multicolumn{6}{|c|}{ Pesticide characteristic or physical and chemical parameters ${ }^{31}$} \\
\hline & $\begin{array}{c}\text { Aqueous Solubility } \\
\left(\mathrm{mg} \mathrm{L}^{-1}\right)\end{array}$ & $\mathrm{K}_{\mathrm{oc}}\left(\mathrm{cm}^{3} \mathrm{~g}^{-1}\right)$ & $\mathrm{K}_{\mathrm{H}}\left(\mathrm{Pa} \mathrm{m}^{3} \mathrm{~mol}^{-1}\right)$ & $\begin{array}{l}\mathrm{t}_{1 / 2} \text { soil } \\
\text { (days) }\end{array}$ & $\begin{array}{l}\mathrm{t}_{1 / 2} \text { water } \\
\text { (days) }\end{array}$ & Result \\
\hline $2,4-\mathrm{D}$ & $20031(\mathrm{pH} 5)$ & 39 & $1.3 \times 10^{-5}$ & 8 & 7.5 & $\mathrm{PC}^{\#}$ \\
\hline Carbofuran & 320 & 22 & $5.1 \times 10^{-4}$ & $30-60$ & $121 \mathrm{pH} 7$ & $\mathrm{PC}$ \\
\hline Clomazone & 1100 & $150-560$ & $4.2 \times 10^{-3}$ & $30-135$ & $>30$ & $\mathrm{PC}$ \\
\hline Tebuconazol & 36 & 4300 & $1 \times 10^{-5}$ & 430 & $7-28$ & $\mathrm{PC}$ \\
\hline
\end{tabular}

\#PC = probable contaminant of groundwaters. $\mathrm{K}_{\mathrm{oc}}$ : partition coefficient normalized to organic carbon; $\mathrm{K}_{\mathrm{H}}$ : Henry's law constant; $\mathrm{t}_{1 / 2}:$ half-life. 
Separations Module fitted with an autosampler, a membrane degasser and a quaternary pump. Mass spectrometry was performed on a Micromass Quattro Micro API with an ESI interface. The LC separation was carried out in an XTerra analytical column $(50 \times 3 \mathrm{~mm}$, i.d. $3.5 \mu \mathrm{m})$ (Waters, Milford, MA, USA). Analytical instrument control, data acquisition and treatment were performed by software Masslynx version 4.1, 2005 (Waters, Milford, MA, USA).

A sample volume of $20 \mu \mathrm{L}$ was injected by an autosampler. The mobile phase was acetonitrile:water $(52: 48, \mathrm{v} / \mathrm{v})$, acidified with $0.1 \%$ formic acid at a constant flow of $0.4 \mathrm{~mL} \mathrm{~min}^{-1}$. Parameters were optimized by continuous infusion of a standard solution $\left(1000 \mu \mathrm{g} \mathrm{L}^{-1}\right)$ via a syringe pump at $10 \mu \mathrm{L} \mathrm{min}{ }^{-1}$ flow rate. Ionization of the compounds was studied by using ESI interface in the positive (PI) and negative (NI) ionization modes. The mass spectrometer was operated in scan, product ion scan and MRM (multiple reaction monitoring) modes. Typical interface conditions were optimized for maximum intensity of the precursor ions as follows: capillary voltage $3.5 \mathrm{kV}$; nebulizer and desolvation (drying gas) flows were set at 350 and $150 \mathrm{~L} \mathrm{~h}^{-1}$, respectively; source block and desolvation temperatures were 120 and $350^{\circ} \mathrm{C}$, respectively. Nitrogen was used as nebulizing, desolvation and cone gas, and argon was used as collision gas.

\section{Analytical parameters}

The validation of the HPLC-DAD procedure had been previously validated and published by Caldas et al. ${ }^{30}$

The performance characteristics of the method for LC-ESI-MS/MS were established by validation procedure and use of standard solutions and spiked samples. Linearity, precision, accuracy (recovery), limits of detection and quantification were evaluated. The linearity was evaluated by using various concentrations of pesticides ranging from 1 to $1000 \mu \mathrm{g} \mathrm{L}^{-1}$ for LC-ESI-MS/MS, with three replicate injections per concentration. The linearity was assessed by linear regression equation $(y=a x+b)$. The results did not show a significant deviation from linearity, which means a correlation coefficient of $r>0.99$.

In this study, LOD and LOQ were determined considering the LOD 3 times the baseline noise and the LOQ the concentration that produced a signal 10 times greater than the baseline noise, in a period close to the retention time of the analyte. ${ }^{32}$ The precision of the method was evaluated in terms of repeatability (RSDr) and expressed as relative standard deviation (RSD). The precision in terms of repeatability was obtained by carrying out the extraction and analysis of fortified samples in three different levels $\left(0.004,0.04\right.$ and $\left.2.0 \mu \mathrm{g} \mathrm{L}^{-1}\right)$, considering the 250-fold SPE preconcentration step. Each spike level was extracted in three replicates and injected three times. The precision of the method, in terms of repeatability (RSDr), was measured by comparing the standard deviations of the responses after nine injections. The accuracy of the method was investigated through mean recoveries. Recovery was determined by adding known amounts of the reference substance at the beginning of the process. Water samples spiked with all pesticides were extracted by applying the SPE method described above. Analyses were carried out in three replicates of blank water samples spiked at three levels for LC-ESI-MS/MS. The accuracy of the method must be in the range $70-120 \%$ at all concentrations with RSD $<20 \% .^{33}$

\section{Results and Discussion}

\section{Chromatographic analysis}

\section{$H P L C-D A D$}

The choice of a proper detection mode is crucial to ensure that all components are detected. With DAD, this problem can be overcome by using a multiple wavelength scanning program, which is capable of monitoring several wavelengths simultaneously. It ensures that all UV-Vis absorbing components are detected. DAD is used to record spectra of compounds from 190 to $400 \mathrm{~nm}$, simultaneously. Analytes identification was accomplished comparing analytes retention times and UV spectra of the standard and detected peak of the sample. Quantification was performed by external calibration and carried out with DAD detection at $220.3 \mathrm{~nm}$. In this wavelength, all compounds present good sensitivity.

The purity of the peaks can be verified in all samples. This can be done by overlapping the spectra of the same peak taken off halfway up the rising side of each peak, at the top of each peak, and halfway down the trailing edge of each peak. If the peak is pure, the overlapped spectra will remain constant throughout the elution of the entire peak.

The main problem of the analysis of water samples using HPLC-DAD is the presence of organic substances, mainly humic and fulvic acids, but it does not interfere in the qualitative and quantitative analysis of the pesticides. The injection of a standard mixture solution prepared in methanol, in a mobile phase based on acetonitrile-ultrapure water, afforded good chromatographic separation for all analytes in $15 \mathrm{~min}$.

\section{LC-ESI-MS/MS}

The LC-ESI-MS/MS technique is proposed in this study as a viable alternative to determine the compounds. 
A mobile phase consisting of acetonitrile and ultrapure water permitted the analysis of all analytes in $3 \mathrm{~min}$. In order to obtain good and reproducible retention times for pesticides and, and for the analysis of acidic compounds, acidification of the mobile phase is recommended. ${ }^{34}$ Formic acid proved to be efficient for ionizing the compounds in question. Under these conditions, a full scan showed that all peaks were resolved.

The chromatograms were recorded in full scan mode with the ESI interface in the positive and negative ionization mode. The scan range was $m / z, 100-350$. The results are shown in Table 2. Three selected pesticides (clomazone, tebuconazole and carbofuran) showed more efficient ionization in the PI mode, whereas only 2,4-D showed preferential ionization in the NI mode. The cone voltage was also optimized because it was considered to be the parameter with the greatest effect on signal sensitivity that could provide information concerning the fragmentation of the compounds under analysis.

To carry out the analysis of all compounds in a single run, the electrospray interface was programmed to change the mode of operation between NI and PI, along the chromatographic analysis. The change of polarity during the acquisition method was performed without any damage in the intensity of the peaks observed.

The advantages supplied by the LC system were strengthened with its coupling to triple quadrupole instruments $(\mathrm{QqQ})$ operating in multiple reaction monitoring mode (MRM). It allowed us to achieve the best sensitivity for the targeted compounds. Moreover, QqQ instruments exhibit excellent quantification abilities owing to their wide linear dynamic range..$^{25}$ The MRM analysis introduces high specificity as it is based on the detection of both a parent ion and one of its known fragments. For each compound, we selected the optimum collision energies with the aim of getting two characteristic MRM transitions with the best signal intensity. We chose the MRM transition with the best signal intensity for quantification. The main advantage of the method was the use of MS/MS because it provides a high level of certainty to identify the target compounds.

\section{Analytical parameters}

The method validation of SPE and HPLC-DAD was published in Caldas et al. ${ }^{30}$ The method using SPE and HPLC-DAD allows a limit of quantification $0.2 \mu \mathrm{g} \mathrm{L} \mathrm{L}^{-1}$, for the compounds assayed, considering a pre-concentration step of 250 -fold. With these limits of detection the HPLC-DAD method could be applied to the analysis of groundwaters since current legislation stipulates a maximum value of $30 \mu \mathrm{g} \mathrm{L}^{-1}$ for 2,4-D, and $7 \mu \mathrm{g} \mathrm{L}^{-1}$ for carbofuran in groundwaters intended for human consumption. The other compounds under investigation are not included in the legislation. ${ }^{35}$

Using LC-ESI-MS/MS, the LOQs were $4.0 \mathrm{ng} \mathrm{L}^{-1}$ for carbofuran, clomazone and tebuconazole and $40.0 \mathrm{ng} \mathrm{L}^{-1}$ for 2,4-D, considering a 250-fold SPE pre-concentration step. It was verified that the obtained LOD and LOQ values were lower for LC-ESI-MS/MS, because of the good sensitivity detection that this ionization mode provides to the polar compounds. Another observable difference was that the matrix effect was more pronounced in HPLC-DAD, while this interference was not observed in LC-ESI-MS/MS.

The low LOQs achieved are an important characteristic of this method because they are close to those required for drinking water, and the groundwater analyzed in this study is intended for direct human consumption. The method guarantees the determination of the pesticides below the maximum concentration established by the Brazilian legislation and the European Union for pesticides in drinking water samples.

All compounds presented excellent linearity within the studied concentration range, from instrumental LOQ values of each compound up to a concentration of $1000 \mu \mathrm{g} \mathrm{L} \mathrm{L}^{-1}$ for

Table 2. Results of the mass spectrometer conditions for the simultaneous analysis of pesticides (dwell time $0.3 \mathrm{~s}$ )

\begin{tabular}{|c|c|c|c|c|c|c|}
\hline Pesticide & Ionization mode & MW & Precursor ion $(\mathrm{m} / \mathrm{z})$ & Product ion $(\mathrm{m} / \mathrm{z})$ & Cone voltage $(\mathrm{V})$ & Collision energy $(\mathrm{eV})$ \\
\hline \multirow[t]{2}{*}{ Carbofuran } & ESI + & 222.3 & 221 & 165 & 20 & 25 \\
\hline & & & & 123 & 20 & 25 \\
\hline \multirow[t]{2}{*}{ Clomazone } & $\mathrm{ESI}+$ & 239.7 & 240 & 125 & 30 & 25 \\
\hline & & & & 219 & 26 & 35 \\
\hline \multirow[t]{2}{*}{ Tebuconazole } & ESI + & 307.8 & 308 & 70 & 40 & 20 \\
\hline & & & & 88 & 33 & 50 \\
\hline \multirow[t]{2}{*}{$2,4-\mathrm{D}$} & ESI - & 221.0 & 219 & 161 & 15 & 20 \\
\hline & & & & 89 & 15 & 30 \\
\hline
\end{tabular}

MW: molecular weight. 
all pesticides. The calibration curves were linear over the whole concentration range tested for all pesticides under study with correlation coefficients (r) better than 0.998 as outlined in Table 3. The precision (repeatability) and the accuracy (recovery), obtained by analyzing in triplicate natural water samples spiked at three different levels for all pesticides under study, are outlined in Table 4. The precision obtained for the overall procedure was similar for both methods SPE and HPLC-DAD, and SPE and LC-ESI-MS/MS; remaining lower than 20\%. Precision may have been mainly governed by the SPE step carried out prior to the chromatographic analysis. The recovery values of all compounds, for both methods, varied from 60.3 up to $108.9 \%$. The values found are considered acceptable for chromatographic methods applied to pesticide residue determinations. ${ }^{33}$

The proposed HPLC-DAD method allowed the analysis of these compounds in less than $15 \mathrm{~min}$. But, with the use of a more selective detector, such as the MS, the time necessary for chromatographic separation is minimized, with less demand on peak resolution. Thus, the LC-ESI-MS/MS permitted the analysis of all analytes under study in $3 \mathrm{~min}$. The influence of the sample matrix was most pronounced in the analyses made by the HPLC-DAD method, with disturbances in base line and background noise. In the LC-ESI-MS/MS method, quantification in the MRM mode solves this problem and the limits of quantification are lower than in HPLC-DAD. So, because of the advantages of the LC-ESI-MS/MS, such as velocity, lower solvent consumption, sensitivity and selectivity, the method using SPE and LC-ESI-MS/MS was chosen for groundwater samples analysis.

\section{Environmental water analysis}

The whole analytical procedure using SPE combined with LC-ESI-MS/MS was applied for determining trace pesticide residues in well water samples taken from ten different wells sites in Quitéria. Quantification was performed by external calibration. Figure 1 show the pesticide levels detected at each location in several sampling campaigns, carried out from September 2007 until August 2008. Results are not surprising at all, since the agricultural

Table 3. Analytical characteristics of methods HPLC-DAD and LC-ESI-MS/MS

\begin{tabular}{lcccccc}
\hline Pesticide & \multicolumn{2}{c}{ Linearity $\left.(\mu \mathrm{g} \mathrm{mL})^{-1}\right)$} & & $\mathrm{r}$ & \multicolumn{2}{c}{ LOQ of the method $\left.(\mu \mathrm{g} \mathrm{L})^{-1}\right)$} \\
& HPLC-DAD & LC-MS/MS & HPLC-DAD & LC-MS/MS & HPLC-DAD & LC-MS/MS \\
\hline Carbofuran & $0.05-10.0$ & $0.001-1.0$ & 0.9994 & 0.9990 & 0.2 & 0.004 \\
2,4-D & $0.05-10.0$ & $0.01-1.0$ & 0.9991 & 0.9982 & 0.2 & 0.04 \\
Clomazone & $0.05-10.0$ & $0.001-1.0$ & 0.9993 & 0.9982 & 0.2 & 0.004 \\
Tebuconazole & $0.05-10.0$ & $0.001-1.0$ & 0.9995 & 0.9992 & 0.2 & 0.004 \\
\hline
\end{tabular}

Table 4. Recovery $(\mathrm{R} \%)$ and Repeatability $\left(\mathrm{RSD}_{\mathrm{r}}\right)$ of methods SPE and HPLC-DAD and SPE and LC-ESI-MS/MS for the mixture of carbofuran, 2,4-D, clomazone and tebuconazole in drinking water samples spiked at different levels

\begin{tabular}{|c|c|c|c|c|c|c|}
\hline \multirow[b]{2}{*}{ Pesticides } & \multicolumn{4}{|c|}{ HPLC-DAD } & \multicolumn{2}{|c|}{ LC-ESI-MS/MS } \\
\hline & $\begin{array}{l}\text { Level } \\
\left(\mu \mathrm{g} \mathrm{L}^{-1}\right)\end{array}$ & $\mathrm{R}(\%)$ & $\operatorname{RSD}_{\mathrm{r}}(\%)$ & $\begin{array}{l}\text { Level } \\
\left(\mu \mathrm{g} \mathrm{L}^{-1}\right)\end{array}$ & $\mathrm{R}(\%)$ & $\operatorname{RSD}_{\mathrm{r}}(\%)$ \\
\hline \multirow[t]{4}{*}{ Carbofuran } & 0.20 & 101.4 & 19.4 & 0.004 & 91.4 & 20.0 \\
\hline & 1.25 & 66.7 & 20.7 & 0.04 & 90.0 & 4.3 \\
\hline & 5.00 & 89.8 & 5.0 & 2.00 & 67.0 & 1.7 \\
\hline & 10.00 & 93.7 & 12.3 & & & \\
\hline \multirow[t]{4}{*}{ 2,4-D } & 0.20 & 60.3 & 12.8 & 0.004 & - & - \\
\hline & 1.25 & 88.7 & 1.0 & 0.04 & 100.0 & 11.6 \\
\hline & 5.00 & 74.4 & 13.1 & 2.00 & 68.1 & 6.8 \\
\hline & 10.00 & 82.7 & 5.0 & & & \\
\hline \multirow[t]{4}{*}{ Clomazone } & 0.20 & 101.8 & 16.2 & 0.004 & 85.9 & 9.9 \\
\hline & 1.25 & 84.4 & 13.2 & 0.04 & 102.9 & 2.6 \\
\hline & 5.00 & 101.1 & 5.7 & 2.00 & 84.6 & 5.7 \\
\hline & 10.00 & 104.3 & 6.6 & & & \\
\hline \multirow[t]{4}{*}{ Tebuconazole } & 0.20 & 98.6 & 17.1 & 0.004 & 108.9 & 20.1 \\
\hline & 1.25 & 100.3 & 19.0 & 0.04 & 90.1 & 1.00 \\
\hline & 5.00 & 107.7 & 8.4 & 2.00 & 105.6 & 2.7 \\
\hline & 10.00 & 92.0 & 2.8 & & & \\
\hline
\end{tabular}

$\mathrm{n}=3$. 
practice in the area is intense and has been going on for years. Carbofuran, clomazone and tebuconazole were the compounds found. In general, significant differences were observed in the levels and the profile of the pesticides detected in distinct sampling periods.
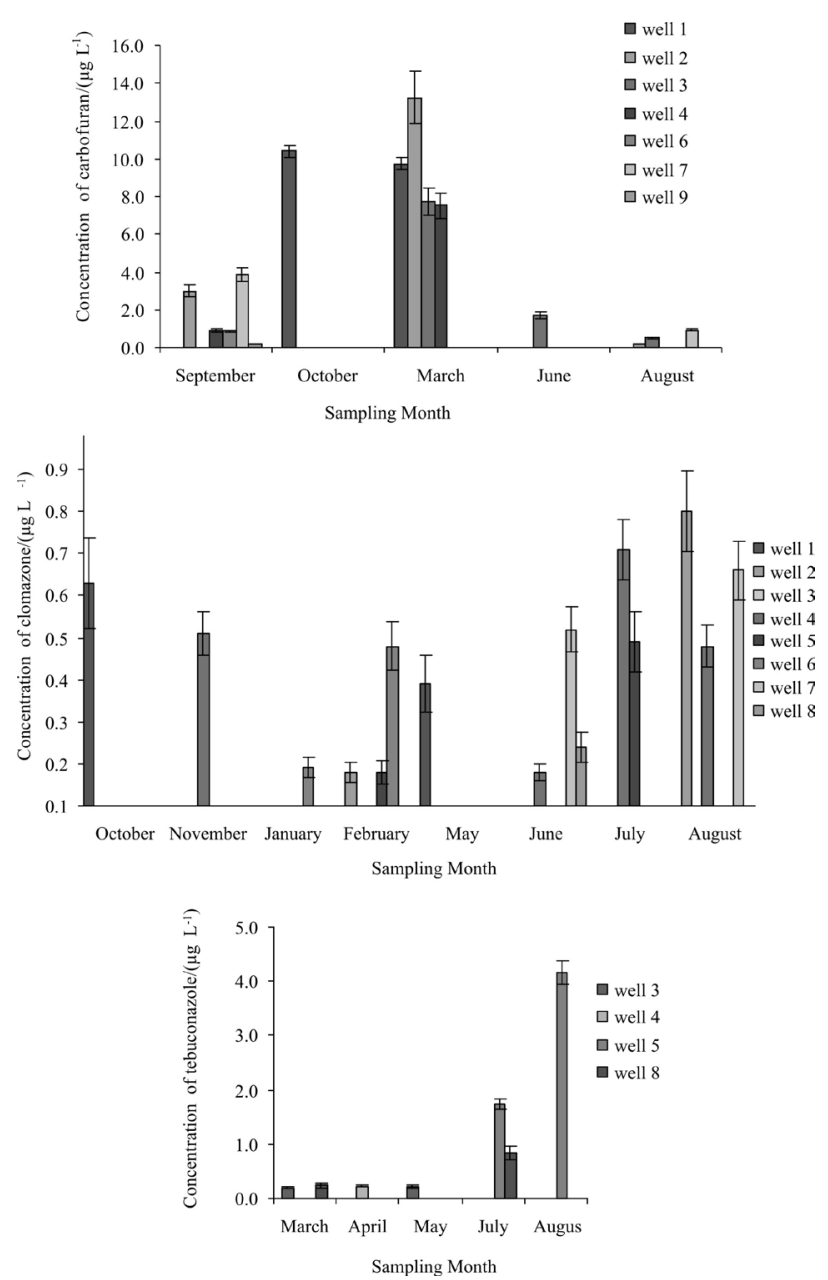

Figure 1. Concentrations of carbofuran, clomazone and tebuconazole $\left(\mu \mathrm{L} \mathrm{L}^{-1}\right)$ in water samples from wells in different months.

The behavior of the samples was strongly different. 2,4-D was the only pesticide that was not detected, probably because it is less used in Quitéria area than the others. It is mainly used in cultures of rice, corn, soy and wheat, ${ }^{36}$ which are not raised in Quitéria. This compound has also lower half life than others and, moreover, has the highest solubility in water and the lowest half life in soil, probably being degraded rapidly before reaching the groundwater. In surface waters, it has been found in many studies. ${ }^{11,19,37}$

The pesticide carbofuran showed the highest concentrations. October and March were the months that showed the highest contamination, 10.4 and $9.75 \mu \mathrm{g} \mathrm{L}^{-1}$, respectively, exceeding the maximum value permitted by the Brazilian legislation for groundwaters. Wells 1
$(9 \mathrm{~m})$ and $2(37 \mathrm{~m})$ presented the major occurrence. Tariq et al..$^{38}$ detected carbofuran residues in well waters from Punjab, Pakistan with a detection frequency of 59 and $43 \%$ in July and October 2004, respectively. This is one of the factors related to the high solubility of the compound in water. The highest concentration was $23.1 \mu \mathrm{g} \mathrm{L}^{-1}$. Bacigalupo and Meroni ${ }^{39}$ analyzed water from wells in an agricultural area in the south of Milan for 11 months and found residues of carbofuran in $90 \%$ of the samples at concentrations below $5.0 \mu \mathrm{g} \mathrm{L} \mathrm{L}^{-1}$. Hernández et al..$^{40}$ detected carbofuran in groundwater in around 25\% of samples (Castellón, Spain), but never in levels higher than $0.1 \mu \mathrm{g} \mathrm{L} \mathrm{L}^{-1}$.

Clomazone has high water solubility and water half life higher than 30 days and showed its highest levels in August in well $2(9 \mathrm{~m}), 0.82 \mu \mathrm{g} \mathrm{L} \mathrm{L}^{-1}$. The high frequency clomazone contamination in groundwaters was detected by Bortoluzzi et al. $;^{5}$ they detected the compound in $50 \%$ of well samples, also in Rio Grande do Sul State at Southeast of Brazil, at a mean concentration of $6.76 \mu \mathrm{g} \mathrm{L}^{-1}$. In this study, the herbicide clomazone was detected in $70 \%$ of wells.

The high detection frequency of the pesticides carbofuran and clomazone in groundwater, both in shallow and deep wells can be explained by their high potential for leaching as a result of their low soil sorption coefficient and high solubility in water, as well as relatively high half life in the soil.

The systemic tebuconazole fungicide is used to control a wide range of fungi on fruit and vegetables. The concentrations of tebuconazole were higher in July and August, and well $5(6 \mathrm{~m})$ showed the highest levels, $1.73 \mu \mathrm{g} \mathrm{L}^{-1}$ in July and $3.65 \mu \mathrm{g} \mathrm{L} \mathrm{L}^{-1}$ in August. The compound tebuconazole was detected in wells $29 \mathrm{~m}$ deep. Although it has occurred with low frequency, it confirms the high potential for leaching that this compound has. This compound was found in groundwaters (in France) by Baugros et al. ${ }^{27}$ The amounts ranged from $0.89 \mu \mathrm{g} \mathrm{L} \mathrm{L}^{-1}$ to $0.03 \mu \mathrm{g} \mathrm{\textrm {L } ^ { - 1 }}$.

A chromatogram obtained from a positive sample by HPLC-DAD and by LC-ESI-MS/MS is shown in Figure 2. Peaks with retention time of 6.601 and 8.930 min were detected in HPLC-DAD and 1.01 and $1.78 \mathrm{~min}$ in LC-ESIMS/MS at $m / z 222>123$ and $240>125$, corresponding to carbofuran and clomazone, respectively.

\section{Conclusions}

The method that we developed showed that SPE proved to be efficient for the extraction of all compounds due to its simplicity, the good recovery results obtained from the spiked water samples, and good data repeatability. 


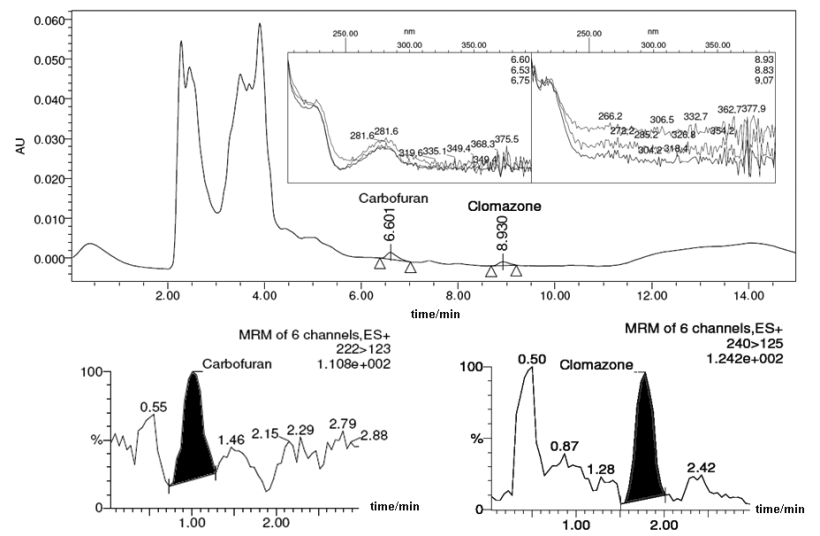

Figure 2. (a) DAD chromatogram corresponding to the analysis of a groundwater sample in which carbofuran $(6.601 \mathrm{~min})$ and clomazone (8.930 min) were detected (inset: absorbance spectra with the purity of the peaks) and (b) MRM extracted ion chromatogram of carbofuran and clomazone by LC-ESI-MS/MS from the same sample.

From the point of view of sensitivity, the SPE method, both with HPLC-DAD and LC-ESI-MS/MS, allowed the determination of pesticides at concentrations below the limits established by the Brazilian legislation in groundwater used for human consumption. However, MS detection shows some advantages in relation to DAD detection, such as structural information. It is very important in order to prevent false positives concerning the identity of compounds in the real samples.

Both methods would be suitable for the simultaneous determination of these pesticides in groundwater samples, and the choice of one procedure over the other may depend on the instrument availability at each laboratory.

In the analysis of the groundwater samples from Quitéria by LC-ESI-MS/MS, three out of the four compounds under investigation were found. The pesticides that we found were carbofuran, clomazone and tebuconazole. Taking into account the ten wells we have analyzed, pollution due to pesticides was found in eight of them, at least once. It should be emphasized that the contents of these pesticides in groundwaters have almost no relation with the time of the analysis, thus, it does not seem to be a seasonal phenomenon. The pollution in groundwaters is persistent and seems to be related to the frequency of pesticide application and rainfall, soil permeability, recharge rate of the aquifer, intensive spraying and the occurrence of specific source contamination due to farmers' lack of knowledge regarding the safe use of pesticides.

\section{Acknowledgments}

The authors acknowledge CNPq, FINEP, CAPES, PETROBRAS and FAPERGS (Term No. 0701984) for financial support.

\section{References}

1. Marchesan, E.; Zanella, R.; Ávila, L. A.; Camargo, E. R.; Machado, S. L. O.; Macedo, V. R. M.; Sci. Agric. (Piracicaba, Braz.) 2007, 64, 131.

2. Marques, M. N.; Cotrim, M. B.; Pires, M. A. F.; Quim. Nova 2007, 30, 1171.

3. Polati, S.; Bottaro, M.; Frascarolo, P.; Gosetti, F.; Gianotti, V.; Gennaro, M. C.; Anal. Chim. Acta 2006, 579, 146.

4. Capobiango, H. L. V.; Cardeal, Z. L.; J. Braz. Chem. Soc. 2005, 16, 907.

5. Bortoluzzi, E. C.; Rheinheimer, D. S.; Gonçalves, C. S.; Pellegrini, J. B. R.; Maroneze, A. M.; Kurz, M. H. S.; Bacar, N. M.; Zanella, R.; Quim. Nova 2007, 30, 1872.

6. Gou, Y.; Eisert, R.; Pawliszyn, J.; J. Chromatogr. A 2000, 873, 137.

7. Chingombe, P.; Saha, B.; Wakeman, R. J.; J. Colloid Interface Sci. 2006, 297, 434.

8. Fonseca, M. B.; Glusczak, L.; Moraes, B. S.; Menezes, C. C.; Pretto, A.; Tierno, M. A.; Zanella, R.; Gonçalves, F. F.; Loro, V. L.; Ecotoxicol. Environ. Saf. 2008, 69, 416.

9. Schriever, C. A.; Von der Ohe, P. C.; Liess, M.; Chemosphere 2007, 68, 2161.

10. Zanella, R.; Primel, E. G.; Machado, S. L. O.; Gonçalves, F. F.; Marchezan, E.; Chromatographia 2002, 55, 573.

11. Primel, E. G.; Zanella, R.; Kurz, M. H. S.; Gonçalves, F. F.; Machado, S. O.; Marchezan, E.; Quim. Nova 2005, 28, 605.

12. Jeannot, R.; Sabik, H.; Sauvard, E.; Genin, E.; J. Chromatogr. A 2000, 879, 51.

13. Rodrigues, A. M.; Ferreira, V.; Cardoso, V. V.; Ferreira, E.; Benoliel, M. J.; J. Chromatogr. A 2007, 1150, 267.

14. Primel, E. G.; Milani, M. R.; Demoliner, A.; Niencheski, L. F.; Escarrone, A. L.; Int. J. Environ. Anal. Chem., in press.

15. Picó, Y.; Fernández, M.; Ruiz, M. J.; Font, G.; J. Biochem. Bioph. Methods 2007, 70, 117.

16. Gatidou, G.; Kotrikla, A.; Thomaidis, N. K. S.; Lekkas, T. D. S.; Anal. Chim. Acta 2005, 528, 89.

17. Bruzzoniti, M. C.; Sarzanini, C.; Costantino, G.; Fungi, M.; Anal. Chim. Acta 2006, 578, 241.

18. Tran, A. T. K.; Hyne, R. V.; Doble, P.; Chemosphere 2007, 67, 944.

19. Palma, G.; Sánchez, A.; Olave, Y.; Encina, F.; Palma, R.; Barra, R.; Chemosphere 2004, 57, 763.

20. Padrón, M. E. T.; Ferrera, Z. S.; Rodríguez, J. J. S.; Anal. Bioanal. Chem. 2006, 386, 332.

21. Rodríguez-Cuesta, M. J.; Boqué, R.; Rius, R. X.; Vidal, J. L. M.; Frenich, A. G.; Chemom. Intell. Lab. Syst. 2005, 77, 251.

22. Slobodnik, J.; Van Baar, B. L. M.; Brinkman, U. A. Th.; J. Chromatogr. A 1995, 703, 81.

23. Vékey, K.; J. Chromatogr. A 2001, 921, 227.

24. Chaves, A.; Shea, D.; Danehower, D.; Chemosphere 2008, 71, 629.

25. Rosen, R.; Curr. Opin. Biotechnol. 2007, 18, 246. 
26. Peschka, M.; Petrovic, M.; Knepper, T. P.; Barceló, D.; Anal. Bioanal. Chem. 2007, 388, 1227.

27. Baugros, J. B.; Giroud, B.; Dessalces, G.; Grenier-Loustalot, M.; Cren-Olivé, C.; Anal. Chim. Acta 2008, 607, 191.

28. Gervais, G.; Brosillon, S.; Laplanche, A.; Helen, C.; J. Chromatogr. A 2008, 1202, 163.

29. Hildebrandt, A.; Guillamón, M.; Lacorte, S.; Tauler, R.; Barcelo, D.; Water Res. 2008, 42, 3315.

30. Caldas, S. S.; Demoliner, A.; Primel, E. G.; J. Braz. Chem. Soc. 2009, 20, 125.

31. Cabrera, L.; Costa, F. P.; Primel, E. G.; Quim. Nova 2008, 31, 1982.

32. Ribani, M.; Collins, C.H.; Bottoli, C.B.G.; J. Chromatogr. A 2007, 1156, 201.

33. Ribani, M.; Bottoli, C. B. G.; Collins, C. H.; Jardim, I. C. F. S.; Melo, L. F. C.; Quim. Nova 2004, 27, 771.

34. Petrovic, M.; Hernando, M. D.; Díaz-Cruz, M. S.; Barceló, D.; J. Chromatogr. A 2005, 1067, 1.

35. Environmental National Council (CONAMA), Resolution No. 396, abril 3, 2008 (Resolução no 396, de 03 de abril de
2008); Deals with classification and environmental guidance for groundwater specifications and other issues (Dispõe sobre a classificação e diretrizes ambientais para o enquadramento das águas subterrâneas e dá outras providências), Diário Oficial da República Federativa do Brasil, 07 abril 2008, Brasil , (http:// www.mma.gov.br/port/conama/legiabre.cfm?codlegi=562).

36. Chemistry Regional Council of the $5^{\text {th }}$ Reigion (Conselho Regional de Química da $5^{\circ}$ região, CRQ-V), Agrotoxic chamber (Camara dos agrotóxicos) First agrotoxic maping used in Rio Grande do Sul ( $I^{o}$ mapeamento de agrotóxicos utilizados no Rio Grande do Sul), $1^{\text {st }}$ ed., CRQ-V: Porto Alegre, 2008.

37. Laganà, A.; Bacaloni, A.; Leva, I.D.; Faberi, A.; Fago, G.; Marino, A.; Anal. Chim. Acta 2002, 462, 187.

38. Tariq, M. I.; Afzal, S.; Hussain, I.; Environ. Int. 2004, 30, 471.

39. Bacigalupo, M. A.; Meroni, G.; J. Agric. Food Chem. 2007, 55 , 3823.

40. Hernández, F.; Sancho, J. V.; Pozo, O.; Lara, A.; Pitarch, E.; J. Chromatogr. A 2001, 939, 1.

Received: June 3, 2009

Web Release Date: December 16, 2009 